\title{
Learning curve of thoracic pedicle screw placement using the free-hand technique in scoliosis: how many screws needed for an apprentice?
}

\author{
Chen Gang $\cdot$ Li Haibo $\cdot$ Li Fancai $\cdot$ \\ Chen Weishan · Chen Qixin
}

Received: 31 January 2011/Revised: 25 October 2011/ Accepted: 3 November 2011/Published online: 12 November 2011

(C) The Author(s) 2011. This article is published with open access at Springerlink.com

\begin{abstract}
Purpose The purpose of this study is to evaluate the learning curve of thoracic pedicle screw (TPS) placement of an inexperienced apprentice in scoliosis with the freehand technique.

Methods The patients with scoliosis who underwent TPS inserted with the free-hand technique by the apprentice under the direction of a chief surgeon were included in this study. The TPS placement by the apprentice was evaluated by examining the assessed position in chronological subgroups of 30 screws. The TPS position was assessed on the postoperative computed tomography (CT) scan images using Zdichavsky grading evaluation system and pedicle breach. The rates of good and dangerous screw placement and the rates of pedicle breaches in each apprentice subgroup were compared with those in the chief surgeon group.

Results Thirty-eight patients with 311 TPS were retrospectively analyzed in our study. Of all screws, 154 pedicle screws were inserted by the apprentice, and were divided chronologically into five subgroups. The rates of dangerous placement performed by the apprentice in the first two subgroups were 26.7 and $23.3 \%$, respectively, and were significantly higher than $9.1 \%$ by the chief surgeon $(P<0.05)$. Meanwhile, the breach rate was $46.6 \%$ in subgroup 1 and $50.0 \%$ in subgroup 2 , and was significantly higher than $29.3 \%$ in chief surgeon $(P<0.05)$. Furthermore, after the first 60 TPS placements, the assessed rates in apprentice reached to a stable level, and no significant
\end{abstract}

C. Gang · L. Haibo · L. Fancai · C. Weishan · C. Qixin $(\square)$ Department of Orthopedic Surgery, The 2nd Affiliated Hospital of Medical College of Zhejiang University, 88 Jiefang Road, Hangzhou 310009, Zhejiang, China

e-mail: bertpumc@yahoo.com difference could be found among the subgroups (subgroup 3,4 and 5) and the chief surgeon group $(P>0.05)$.

Conclusions For an apprentice, an experience of at least 60 screw placements under the direction of an experienced surgeon is needed for inserting the TPS in scoliosis using the free-hand technique independently.

Keywords Free-hand technique - Learning curve · Scoliosis - Thoracic pedicle screw

\section{Introduction}

Pedicle screws have been used widely for spine diseases since the 1960s when first reported by Roy-Camille [1, 2]. Compared with hooks and other instruments, pedicle screws enable better correction, higher rates of fusion, and lower rates of revision [3-8]. Since Suk [9] reported the use of thoracic pedicle screws (TPS) for scoliosis in the 1990s, pedicle screw fixation has become the primary choice for the posterior approach surgery for scoliosis. The free-hand technique is a method of inserting pedicle screw without using any special instrumentation and has become one of the most popular techniques [3]. However, this will put more demands on the surgeon because of morphology features and anatomical variation of the thoracic pedicles in scoliosis and the associated potential complications of injury to the adjacent structures caused by malposition of the TPS. It is still a challenge for the spinal surgeons especially for an inexperienced apprentice.

It is an important question for a surgeon when he could have acquired the free-hand technique of TPS insertion in scoliosis. Studies on the learning curve for different surgical procedures revealed a steady stage defined as asymptote of the learning curve, which meant the 
acquirement of a technique [10,11]. Several studies have described the improvement of the pedicle screw placement in spine with the accumulation of experience [11-13]. However, no one has defined the actual number of TPS or cases necessary to be competent in the free-hand technique for patients with scoliosis. In the present study, the accuracy of TPS placement by one apprentice has been retrospectively analyzed with a grading scale of TPS and pedicle breach, and compared with that by chief surgeon. The purpose of our study is to evaluate the learning curve for insertion of TPS and ascertain the number of screw insertion needed for an apprentice to acquire the free-hand technique of TPS placement in scoliosis.

\section{Materials and methods}

\section{General data}

An apprentice entered a training program for surgery of scoliosis from January 2007 to December 2009 in our department. The apprentice had had the good experience of TPS placement in spine without deformity before that time. In the training progress of 2 years, the apprentice finished the TPS placement under the direction of one chief surgeon who had inserted pedicle screws in deformed thoracic spine for more than 2 years.

\section{Surgical technique}

We used the free-hand technique described by Lenke [3] for inserting pedicle screws. After making a midline incision, the spinal segment was exposed carefully to the tips of the transverse processes bilaterally. The entry point was identified using posterior landmarks and decorticated using a rongeur. Proper placement of the gearshift probe is critical. The probe should feel snug in the cancellous bone, and any sudden advance or persistent resistance indicates that the probe should be repositioned. Once the tract was made, a flexible ball-tip probe was used to palpate and ensure that the bony walls and floor were intact. Then, after tapping and palpation, the screws were inserted. C-arm fluoroscopy was performed to establish the position of the screws, particularly in the lateral view, and misplaced screws were re-inserted.

Evaluation of TPS placement

The accuracy of TPS position was assessed on postoperative CT (transverse plane) using Zdichavsky grading system and pedicle breach. The Zdichavsky grading system was done to evaluate the accuracy of TPS placement as following [14]: grade Ia, optimally placed screws, rigidly anchored within the pedicle and vertebral body; grade Ib, screws placed with
$>50 \%$ of the pedicle screw diameter (PSD) lateral outside the pedicle and with $>50 \%$ of the PSD within the vertebral body; grade IIa, screws placed with $\geq 50 \%$ of the PSD within the pedicle and $>50 \%$ of the PSD outside the lateral cortex of the vertebral body; grade IIb, screws placed with $\geq 50 \%$ of the PSD within the pedicle and the tip of the screw crossing the midline of the vertebral body; grade IIIa, screws located with $>50 \%$ of the PSD outside the pedicle and lateral vertebral cortex; and grade IIIb, screws located with $>50 \%$ of the PSD outside the pedicle medially and the tip of the screw crossing the midline of the vertebral body with spinal canal encroachment (Fig. 1). The TPS in grade I (grade Ia and Ib) was recorded as a good placement, and grade III (grade IIIa and (IIIb) as a dangerous placement.

Pedicle breach was assessed to enhance the credibility of the evaluation of TPS placement. As Amer [12] described, the breach was defined as the pedicle wall encroached by more than $2 \mathrm{~mm}$. Moreover, the pedicle breach was classified as either lateral or medial according the pedicle wall breached (Fig. 2).

Two spine surgeons conducted the evaluation of the CT images of the TPS independently. Disagreements on the grading were settled through evaluation by a third surgeon; thus, the results recorded were concordant with at least two readings.

To analyze the learning curve of the apprentice, the TPS of the apprentice were arranged in chronological order in 5 subgroups of 30 screws each, and the last subgroup contained 34 screws. The rates of good (grade I) and dangerous (grade III) placement, breach rates of each subgroup were calculated and compared with those of the chief surgeon to analyze the variation with increasing experience.

The accuracy of TPS of the chief surgeon was considered as the reference of the learning objective, and we assumed the chief surgeon had entered the Asymptote stage of the learning curve. The TPS of the chief surgeon were divided into subgroups in the same way as the apprentice, and the intro-subgroup difference was analyzed to confirm the assumption.

\section{Statistical analysis}

SPSS ver. 17 software (SPSS, Inc., Chicago, IL, USA) was used for statistical analysis. Chi-square test was used for categorical variables including the rates of good placement, rates of dangerous placement and rates of breach.

\section{Results}

Thirty-eight patients (10 males, 28 females) with scoliosis who underwent pedicle screw placement in the thoracic spine between January 2007 and December 2009 were 
Fig. 1 Grading system described by Zdichavsky (15): grade Ia (a): optimally placed screws, rigidly anchored within the pedicle and vertebral body; grade $\mathrm{Ib}(\mathbf{b})$ : screws placed with $>50 \%$ of the pedicle screw diameter (PSD) lateral outside of the pedicle and with $>50 \%$ of the PSD within the vertebral body; grade IIa (c): screws placed with $\geq 50 \%$ of the PSD within the pedicle and $>50 \%$ of the PSD outside the lateral cortex of the vertebral body; grade IIb (d): screws placed with $\geq 50 \%$ of the PSD within the pedicle and the screw tip crossing the midline of the vertebral body; grade IIIa (e): screws located with $>50 \%$ of the PSD outside the pedicle and lateral vertebral cortex and grade IIIb (f): screws located with $>50 \%$ of the PSD outside the pedicle medially and the screw tip crossing the midline of the vertebral body with spinal canal encroachment
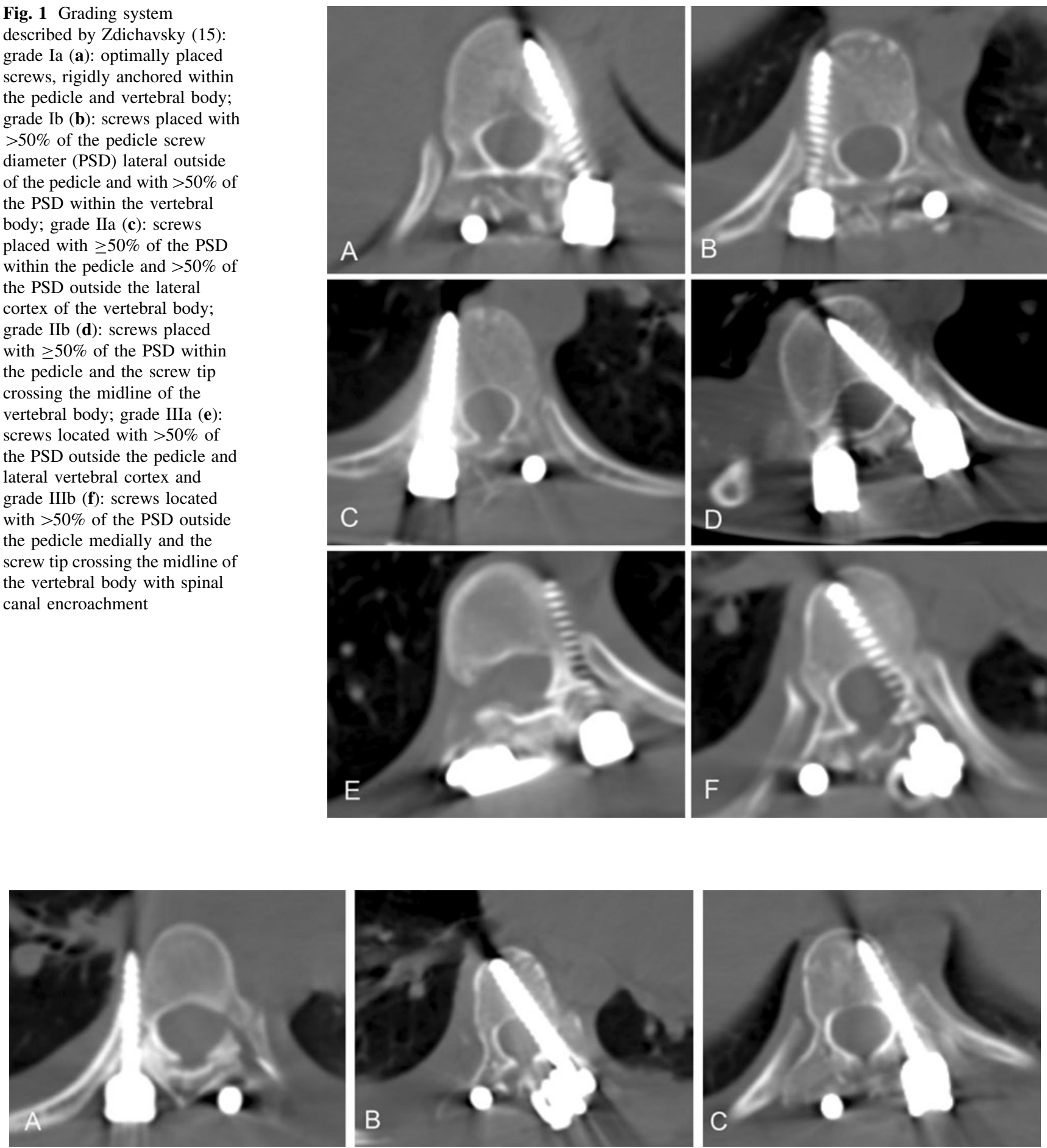

Fig. 2 The assessment of TPS breach. a Lateral breach, b medial breach, $\mathbf{c}$ no breach

reviewed in our study. There were 30 patients with idiopathic scoliosis and 8 with neurofibromatosis. The average angle of the main thoracic curve was $67.3^{\circ}$ (range $\left.44-107^{\circ}\right)$. In total, 311 screws were inserted in thoracic pedicles. The apprentice finished 154 screws and the chief surgeon finished 157 screws.
One patient had transient paralysis of the tibialis anterior muscle, and recovered 4 months later without revision. The CT images showed that a pedicle screw breached the medial pedicle wall more than $8 \mathrm{~mm}$ on the right pedicle of the eighth thoracic vertebra, and that pedicle screw was inserted by the apprentice. 


\section{TPS of the chief surgeon}

The rate of the good placement was $82.2 \%$, and the rate of dangerous placement was $9.1 \%$. The rate of breach was $29.3 \%$ (21.7\% lateral and $7.6 \%$ medial). The TPS of the chief surgeon were divided into 5 subgroups of 30 pedicles. No difference of the assessed rates was found between the subgroups (Tables 1, 2), which meant that the learning curve in the chief surgeon had reached to a stable plate (Asymptote stage).

TPS of the apprentice

The good placement rates of subgroup 1 and 2 were both $70.0 \%$, which were lower than that of the chief surgeon but no significant difference $(P=0.062)$. On the other hand, the rates of dangerous placement of subgroup 1 and 2 were significantly higher than that of the chief surgeon $(26.7 \%$ in subgroup $1, P=0.007 ; 23.3 \%$ in subgroup $2, P=0.025$ ); there was no significant difference among the subgroup 3 , 4, 5 of the apprentice and the chief surgeon (Table 3).

The breach rate of the subgroups 1 and 2 was significantly high than the chief surgeon. The same trend of the breach rate was found with the rates of the dangerous placement. There was no difference from the subgroup 3 to 5 compared with the chief surgeon. The lateral breach rate of subgroup $2(40.4 \%, P=0.033)$ and the medial breach rate of subgroup $1(27.6 \%, P=0.047)$ are higher than the chief surgeon. With the increasing number of TPS placements, the breach rates decreased on both the lateral and medial walls (Table 4).

\section{Discussion}

Because of the technical difficulty of accurate placement of screws into the thoracic pedicles, Vaccaro [5] had suggested that pedicle screw fixation in the thoracic spine may be restricted to patients who have a deficiency of posterior bony elements or a three-column injury with complete damage of the spinal cord. The malposition with TPS placement may be due to the smaller diameters of thoracic pedicles. In scoliosis, abnormal rotation of the pedicles and displacement of the spinal cord and dural sac will increase the rate of malposition because of the limited safe margin for TPS placement [1517]. Thereafter, the increase in rate of intra-operative replacement of TPS has been reported. In another study of our group, there were 11 malpositions $(3.5 \%)$ found using the C-arm fluoroscopy, and reposition was performed [18]. Complications caused by malpositioned screws in thoracic region have been reported including injuries of the spinal cord, blood vessels and pleura [4, 19, 20]. In our series, we encountered one case with paralysis of the tibialis anterior muscle. The CT images showed one pedicle screw breaching the medial wall more than $8 \mathrm{~mm}$ on the right pedicle of the eighth thoracic vertebra.

The analysis of the learning curve is based on the assessment of the accuracy of each TPS. The breach rate of TPSs ranges from 1.5 to $58 \%$, and is related to the evaluation methods used, which are typically roentgenogram and CT scans [3, 4, 12, 21]. Ferrick [22] considered that the roentgenogram is inadequate to assess the pedicle position, as the accuracy rate of plain film only ranged from 73 to $83 \%$. A CT scan provides better accuracy to evaluate the breach of the pedicle wall, which is considered as the golden standard for evaluating the position of pedicle screws [6, 22-24]. It is difficult to measure the breach length less than $2 \mathrm{~mm}$ on the CT images, partly because the screws could generate scatter [25, 26]. Moreover, some studies considered that the penetration of the pedicle wall was not the most relevant parameter for pedicle screw placement [14]. To avoid those effects and enhance the reliability of evaluation, we selected both a grading scale described by Zdichavsky and the pedicle breach assessment to evaluate the accuracy of TPS.

Surgeon experience may play an important role in TPS placement, especially with the free-hand technique. Lehman's [27] study indicated that the accumulation of experience increases the accuracy rate of breaching with a ball-tip probe. Experience also means lower breaching rates of the medial and lateral wall, as Amer [12] described. The analysis of the TPS placement of the chief surgeon in the

Table 1 Rates of good placement and dangerous placement of the TPS inserted by the chief surgeon

\begin{tabular}{lccccc}
\hline Subgroup & & & & In total & $P$ (Chi-square test) \\
\hline 1 & 3 & 4 & 5 & \\
\hline $\begin{array}{l}\text { Rate of good placement \% } \\
76.6\end{array}$ & 83.3 & 86.7 & 81.1 & 82.2 & 0.440 \\
$\begin{array}{l}\text { Rate of dangerous placement\% } \\
6.3\end{array}$ & 13.6 & 3.3 & 5.4 & 9.1 & 0.304 \\
\hline
\end{tabular}

The pedicle screws inserted by the chief surgeon were divided into 5 subgroups of 30 screws in chronological order. For the rate of good placement and dangerous placement, there was no significant difference among the subgroups using the Chi-square test 
Table 2 Breach rates of the TPS inserted by the chief surgeon

\begin{tabular}{|c|c|c|c|c|c|c|}
\hline \multicolumn{5}{|c|}{ Subgroup } & \multirow[t]{2}{*}{ In total } & \multirow[t]{2}{*}{$P($ Chi-square test $)$} \\
\hline 1 & 2 & 3 & 4 & 5 & & \\
\hline \multicolumn{7}{|c|}{ Breach rate of medial wall\% } \\
\hline 6.7 & 3.3 & 10.0 & 3.3 & 16.2 & 8.5 & 0.440 \\
\hline \multicolumn{7}{|c|}{ Breach rate of lateral wall\% } \\
\hline 20.0 & 30.0 & 26.7 & 23.3 & 10.8 & 21.7 & 0.131 \\
\hline \multicolumn{7}{|c|}{ Total breach rate $\%$} \\
\hline 26.7 & 33.3 & 36.7 & 26.6 & 27.0 & 30.2 & 0.898 \\
\hline
\end{tabular}

No significant difference was found between the subgroups of the chief surgeon using the Chi-square test

Table 3 Rates of good placement and dangerous placement of the TPS inserted by the apprentice

\begin{tabular}{llll}
\hline Subgroup & & & \\
\hline 1 & 2 & 3 & 4 \\
\hline $\begin{array}{l}\text { Rate of good placement } \% \\
70.0^{*}(P=0.062)\end{array}$ & $70.0^{*}(P=0.062)$ & 76.7 & 86.7 \\
$\begin{array}{l}\text { Rate of dangerous placement } \% \\
26.7 *(P=0.007)\end{array}$ & $23.3^{*}(P=0.025)$ & 10 & 10 \\
\hline
\end{tabular}

The TPS inserted by the apprentice were divided into five subgroups of 30 screws except for the last subgroup, which contained 34 screws. The rates of good and dangerous placement of each subgroup were calculated and compared with those of the chief surgeon

* Difference occurred in subgroups of the apprentice compared with those of the chief surgeon (Chi-square test)

Table 4 Breach rates of the TPS inserted by the apprentice

\begin{tabular}{|c|c|c|c|c|}
\hline \multicolumn{5}{|l|}{ Subgroup } \\
\hline 1 & 2 & 3 & 4 & 5 \\
\hline \multicolumn{5}{|c|}{ Breach rate of medial wall\% } \\
\hline 26.7 & $40.0^{*}(P=0.033)$ & 23.3 & 23.3 & 26.5 \\
\hline \multicolumn{5}{|c|}{ Breach rate of lateral wall\% } \\
\hline $26.7 *(P=0.047)$ & 10 & 10 & 6.7 & 5.9 \\
\hline \multicolumn{5}{|l|}{ Total breach rate $\%$} \\
\hline $46.6 *(P=0.05)$ & $50.0^{*}(P=0.027)$ & 33.3 & 31.0 & 32.4 \\
\hline
\end{tabular}

* Significant difference was found between the subgroups 1, 2 of the apprentice and the rates of the chief surgeon using the Chi-square test

present study showed no significant difference of Zdichavsky grading scale and pedicle breach among the subgroups. The fact confirmed that the chief surgeon had acquired the TPS free-hand skill in patients with scoliosis and had reached to the steady state (asymptote) in a learning curve.

Gonzalvo et al. [11] found that there was a significant reduction in the number of misplaced screws and the development of an asymptote after approximately 80 screws. The study, however, was based on the learning progress of a totally inexperienced fellow, and the pedicle screws were inserted in the thoracic and lumbar spine without deformity. In our study, although the apprentice had acquired the TPS free-hand skill on normal pedicles, it was found that the rate of malposition of the first 60 TPS was also significantly higher than the chief surgeon group.
The result indicated that the learning program is important for the spinal surgeon without experience of TPS insertion in scoliosis despite his TPS insertion skill in patients without spine deformity before. The further results showed that with the accumulation of experience, the rates of good placement increased and the rates of dangerous placement decreased; and the breach rates of the lateral and medial wall also decreased. The accuracy of TPS placement could reach to a stable and acceptable level after the first 60 screw placements under the direction of an experienced surgeon. Thus, we believed that a surgeon should acquire the experience of TPS insertion on normal pedicles before he begins to learn the free-hand technique in scoliosis. Furthermore, a training program of 60 TPS insertion under the direction of an experienced surgeon is needed. 
The limitation in our study is the insufficient number of the concave peri-apical pedicle screws, and those pedicles pose more difficulties for TPS placement. Most of the main curves in thoracic spine are toward the right side [12, 28, 29]. In our study, the apprentice always stood on the right side of the patients, and that means he did not have enough exercise on the concave peri-apical pedicles of the severe curve.

\section{Conclusions}

Finally, for surgeons who want to receive training in the free-hand technique of TPSs placement in scoliosis, the following should be considered: (1) the apprentice should first develop experience in inserting TPS in spine without deformity; (2) it is necessary to insert at least 60 screws under the direction of an experienced surgeon; and (3) preoperative safety assessment for screw placement is necessary. Only when the accuracy of TPS reaches an acceptable level, the surgeon can be permitted to insert TPSs independently. Finally, (4) more training is still needed for TPS insertion on the concave peri-apical pedicles of severe curves.

\section{Conflict of interest None.}

Open Access This article is distributed under the terms of the Creative Commons Attribution Noncommercial License which permits any noncommercial use, distribution, and reproduction in any medium, provided the original author(s) and source are credited.

\section{References}

1. Roy-Camille R, Saillant G, Mazel C (1986) Internal fixation of the lumbar spine with pedicle screw plating. Clin Orthop Relat Res 203:7-17

2. Roy-Camille R, Saillant G, Mazel C (1986) Plating of thoracic, thoracolumbar, and lumbar injuries with pedicle screw plates. Orthop Clin North Am 17:147-159

3. Kim YJ, Lenke LG, Bridwell KH (2004) Free hand pedicle screw placement in the thoracic spine: is it safe? Spine 29:333-342

4. Suk SI, Kim WJ, Lee SM (2001) Thoracic pedicle screw fixation in spinal deformities: are they really safe? Spine 26:2049-2057

5. Vaccaro AR, Garfin SR (1995) Internal fixation (pedicle screw fixation) for fusion of the lumbar spine. Spine 20:157S-165S

6. Belmont PJ Jr, Kleme WR, Robinson M, Polly DW Jr (2002) Accuracy of thoracic pedicle screws in patients with and without coronal plane spinal deformities. Spine 27:1558-1566

7. Liljenqvist U, Hackener L, Link T (2001) Pullout strength of pedicle screws versus pedicles and laminar hooks in the thoracic spine. Acta Orthop Belg 67:157-163

8. Hackenberg L, Link T, Liljenqvist U (2002) Axial and tangential fixation strength of pedicle screws versus hooks in the thoracic spine in relation to bone mineral density. Spine 37:937-942

9. Suk SI, Lee CK, Kim WJ (1995) Segmental pedicle screw fixation in the treatment of thoracic idiopathic scoliosis. Spine 20:1399-1405
10. Nowitzke A (2005) Assesment of the learning curve for lumbar microendoscopic discectomy. Neurosurgery 56:755-762

11. Gonzalvo A, Fitt G, Liew S, de la Harpe D, Turner P, Ton L, Rogers MA, Wilde PH (2009) The learning curve of pedicle screw placement: how many screws are enough? Spine 34:E761E765

12. Samdani AF, Ranade A (2010) Learning curve for placement of thoracic pedicle screws in the deformed spine. Neurosurgery 66:290-295

13. Lehman RA Jr, Lenke LG, Keeler KA, Kim YJ (2007) Computed tomography evaluation of pedicle screws placed in the paediatric deformed spine over an 8-year period. Spine 32:2679-2684

14. Zdichavsky M, Blauth M, Knop C (2004) Accuracy of pedicle screw placement in thoracic spine fractures: part I: inter- and intraobserver reliability of the scoring system. Eur J Trauma 30:234-240

15. Sucato DJ, Duchene C (2003) The position of the aorta relative to the spine: a comparison of patients with and without idiopathic scoliosis. J Bone Joint Surg Am 85-A:1461-1469

16. Sucato DJ, Kassab F, Dempsey M (2004) Analysis of screw placement relative to the aorta and spinal canal following anterior instrumentation for thoracic idiopathic scoliosis. Spine 29:554-559

17. Polly DW Jr, Potter BK, Kuklo T, Young S et al (2004) Volumetric spinal canal intrusion, a comparison between thoracic pedicle screws and thoracic hooks. Spine 29:63-69

18. Xu WX, Chen QX, Li FC (2008) Research on safe implantation of upper-middle thoracic pedicle screws under the X-ray perspective. Zhongguo Gu Shang 21:106-108

19. Kakkos SK, Shepard AD (2008) Delayed presentation of aortic injury by pedicle screws: report of two cases and review of the literature. J Vasc Surg 47:1074-1082

20. Heini P, Scholl E, Wyler D (1998) Fatal cardiac tamponade associated with posterior spinal instrumentation: a case report. Spine 23:2226-2230

21. Smorgick Y, Millgram MA, Anekstein Y (2005) Accuracy and safety of thoracic pedicle screw placement in spinal deformities. J Spinal Disord Tech 18:522-526

22. Ferrick MR, Kowalski JM, Simmons ED (1997) Reliability of roentgenogram evaluation of pedicle screw position. Spine 22:1249-1253

23. Kim YJ, Lenke LG, Cheh G et al (2005) Evaluation of pedicle screw placement in the deformed spine using intraoperative plain radiographs: a comparison with computerized tomography. Spine 30:2084-2088

24. Rajasekaran S, Vidyadhara S, Ramesh P, Shetty AP (2007) Randomized clinical study to compare the accuracy of navigated and non-navigated thoracic pedicle screws in deformity correction surgeries. Spine 32:E56-E64

25. Choma TJ, Denis F, Lonstein JE et al (2006) Stepwise methodology for plain radiographic assessment of pedicle screw placement: a comparison within computed tomography. J Spinal Disord Tech 19:547-553

26. Ebraheim NA, Rupp RE, Savolaine ER (1994) Use of titanium implants in pedicular screw fixation. J Spinal Disord 7:478-486

27. Lehman RA, Potter BK, Kuklo TR (2004) Probing for thoracic pedicle screw tract violation(s): is it valid? J Spinal Disord Tech 17:277-283

28. Catan H, Buluç L, Anik Y, Ayyildiz E, Sarlak AY (2007) Pedicle morphology of the thoracic spine in preadolescent idiopathic scoliosis: magnetic resonance supported analysis. Eur Spine J 16:1203-1208

29. Liljenqvist UR, Link TM, Halm HF (2000) Morphometric analysis of thoracic and lumbar vertebrae in idiopathic scoliosis. Spine 25:1247-1253 